\title{
Ocean Cooling Pattern at the Last Glacial Maximum
}

\author{
Kelin Zhuang ${ }^{1}$ and John R. Giardino ${ }^{2}$ \\ ${ }^{1}$ University of Arizona, Tucson, Arizona, AZ 85721, USA \\ ${ }^{2}$ Texas A\&M University, College Station, Texas, TX 77843, USA \\ Correspondence should be addressed to Kelin Zhuang, klzhuang@hotmail.com
}

Received 3 May 2012; Revised 13 August 2012; Accepted 13 August 2012

Academic Editor: Youmin Tang

Copyright ( $\odot 2012$ K. Zhuang and J. R. Giardino. This is an open access article distributed under the Creative Commons Attribution License, which permits unrestricted use, distribution, and reproduction in any medium, provided the original work is properly cited.

Ocean temperature and ocean heat content change are analyzed based on four PMIP3 model results at the Last Glacial Maximum relative to the prehistorical run. Ocean cooling mostly occurs in the upper $1000 \mathrm{~m}$ depth and varies spatially in the tropical and temperate zones. The Atlantic Ocean experiences greater cooling than the rest of the ocean basins. Ocean cooling is closely related to the weakening of meridional overturning circulation and enhanced intrusion of Antarctic Bottom Water into the North Atlantic.

\section{Introduction}

The cooling at the Last Glacial Maximum has been extensively studied geologically and numerically (e.g., [1-5]) where proxy data and numerical modeling were both employed to explore the climate sensitivity and mechanism. The Paleoclimate Modeling Intercomparison Project (PMIP2) presented large-scale features (e.g., [6]). However, the spatial pattern of cooling at that period was little studied previously. In this paper we use the newly released PMIP3 data to study the cooling pattern at the Last Glacial Maximum.

\section{Methods}

We analyze ocean potential temperature anomaly, ocean heat content $(\mathrm{OHC})$ change, and meridional overturning mass stream function based on four available PMIP3 models of IPSL-CM5A-LR, MIROC-ESM, MPI-ESM-P, and MRI-CGCM3 so far (http://cmip-pcmdi.llnl.gov/cmip5/), which follow the PMIP3 21ka experimental design (Table 1; http://pmip3.lsce.ipsl.fr/) and make a comparison between the last 50 years of Last Glacial Maximum (LGM) experiments relative to the base period of the last 50 years of the preindustrial control run.
We calculate the temperature anomaly, meridional overturning mass stream function anomaly, and ocean heat content change of each model by regridding all the temperature data into a common $1^{\circ} \times 1^{\circ}$ grid.

\section{Results}

3.1. Geographical Distribution. Ocean cooling shows pronounced spatial variations (Figure 1), both horizontally and vertically. The Northern Hemisphere exhibits a stronger cooling than the Southern Hemisphere of IPSL-CM5A-LR, MIROC-ESM, and MPI-ESM-P except MRI-CGCM3 with stronger cooling in the Southern Ocean revealing a notable north-south asymmetry.

At the surface (Figures 1(a) and 1(b)), significant ocean cooling $\left(<-5^{\circ} \mathrm{C}\right)$ occurs in the North Pacific and North Atlantic of the first three models. All these three models have shown the maximum cooling regions in the North Pacific around $40^{\circ} \mathrm{N}$ and in the Nordic Seas. But, MRICGCM3 demonstrates a significant cooling around $60^{\circ} \mathrm{S}$ in the Southern Ocean. It is of note that south of Greenland the model even shows a slight warming in shallow water.

At the subsurface $500 \mathrm{~m}$ layer (Figure 1(c)) cooling in the Pacific around $40^{\circ} \mathrm{N}$ and the North Atlantic still maintain 

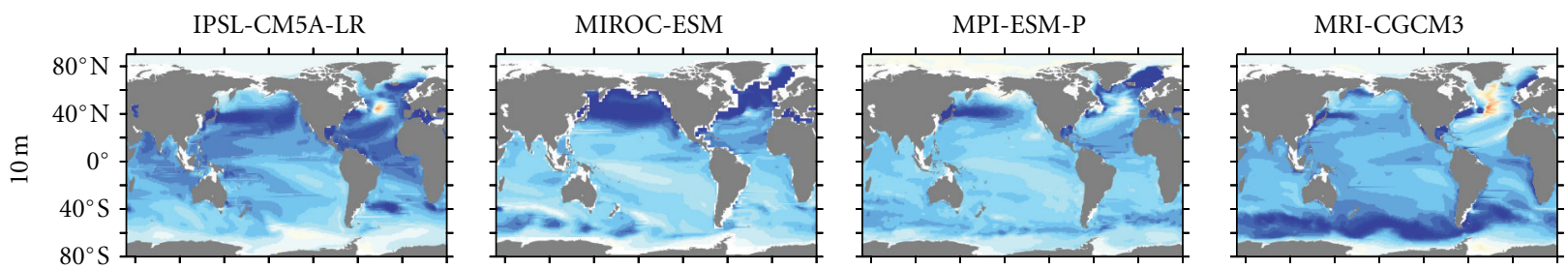

(a) $10 \mathrm{~m}$
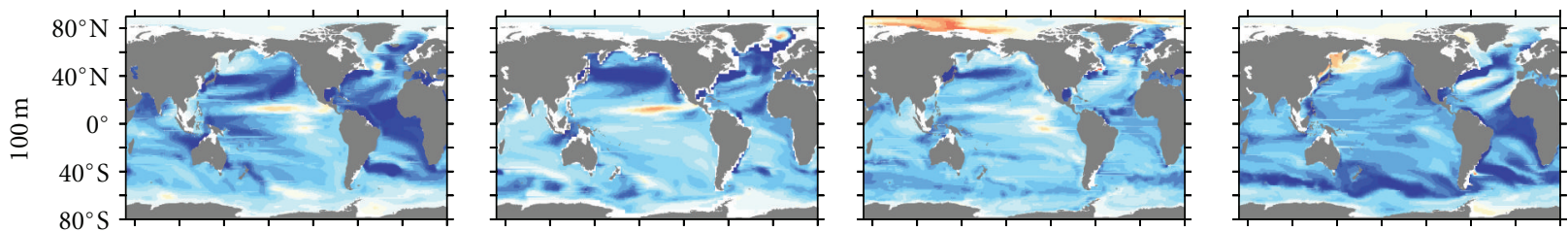

(b) $100 \mathrm{~m}$
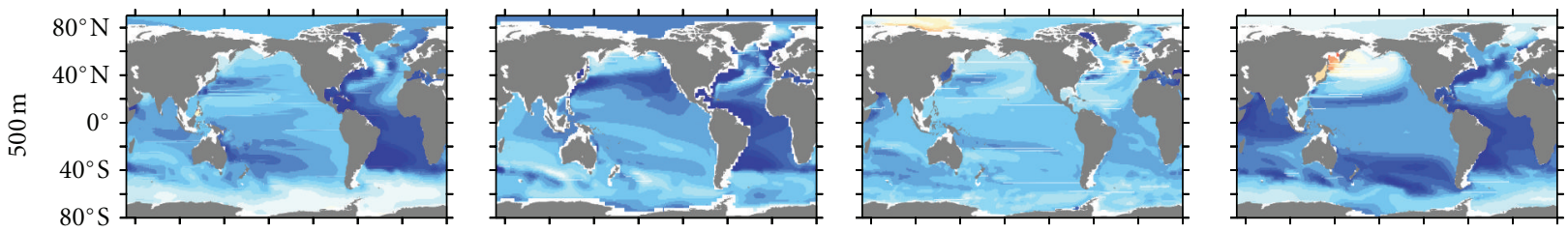

(c) $500 \mathrm{~m}$
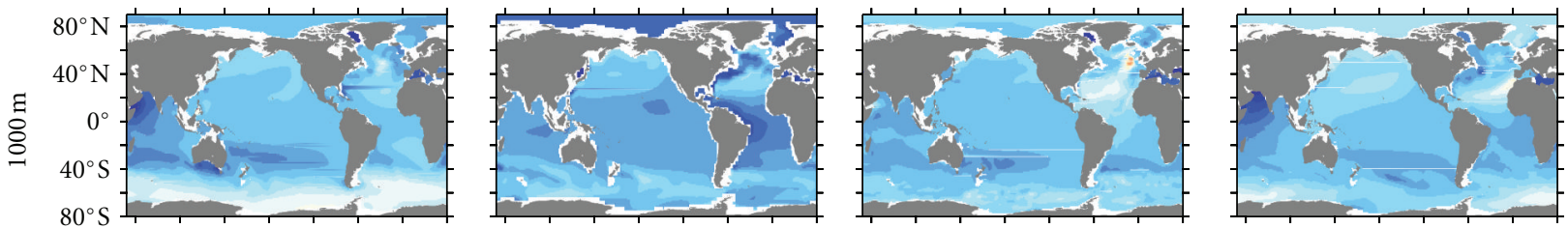

(d) $1000 \mathrm{~m}$
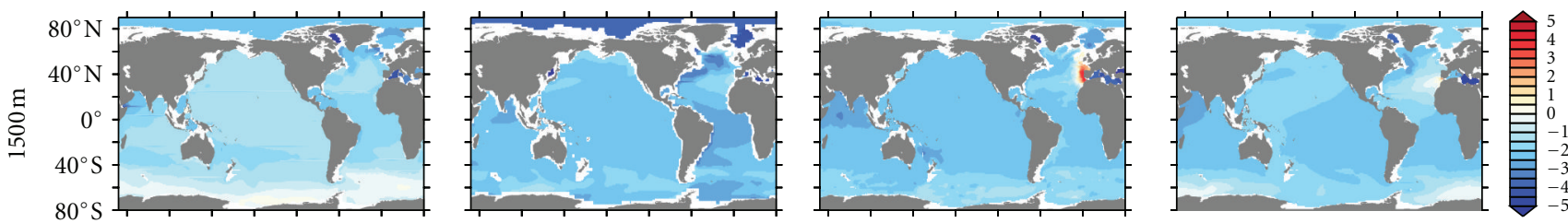

(e) $1500 \mathrm{~m}$
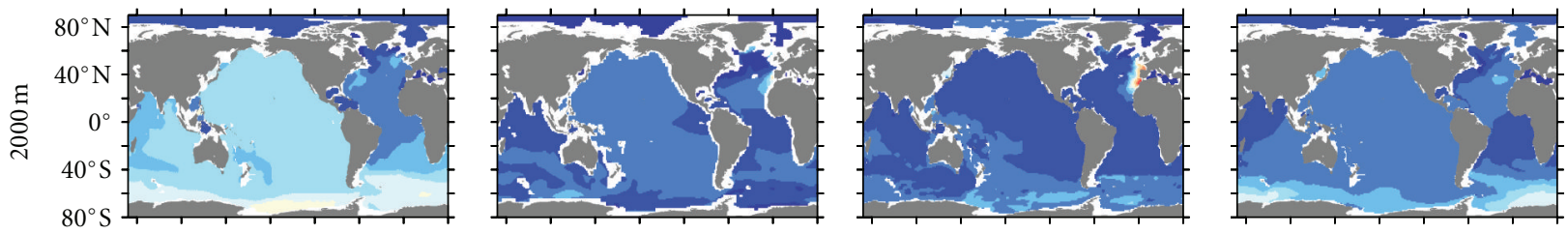

(f) $2000 \mathrm{~m}$
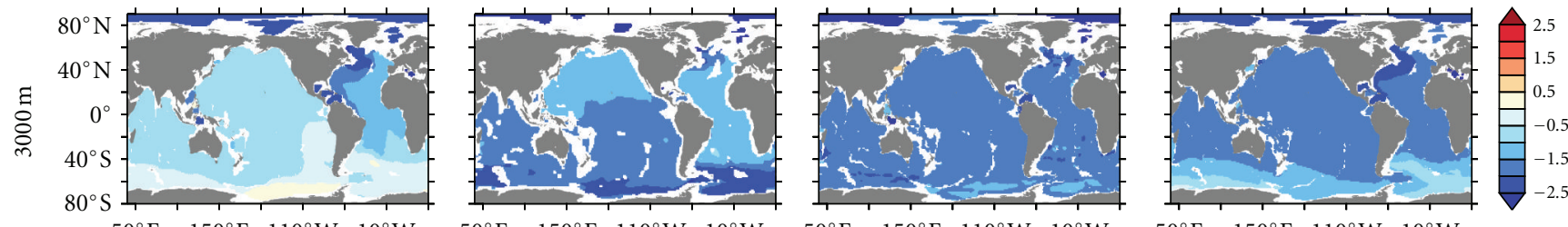

(g) $3000 \mathrm{~m}$

Figure 1: Geographical distribution of potential temperature anomaly in ${ }^{\circ} \mathrm{C}$ at different water depths. The abscissa is longitude in degrees and the ordinate is latitude in degrees. See text for detailed description. 
TABLE 1: PMIP3 LGM models.

\begin{tabular}{lccr}
\hline Model & Atmosphere & Ocean & Data output coverage \\
\hline IPSL-CM5A-LR & $96 \times 95 \times$ L39 & $182 \times 149 \times$ L31 & $4600-4699(100$ years $)$ \\
MIROC-ESM & $128 \times 64 \times$ L80 & $256 \times 192 \times$ L44 & $2501-2600(100$ years $)$ \\
MPI-ESM-P & $196 \times 98 \times$ L47 & $256 \times 220 \times$ L40 & $1850-1949(100$ years $)$ \\
MRI-CGCM3 & $320 \times 160 \times$ L48 & $364 \times 368 \times$ L51 & $2501-2600(100$ years $)$ \\
\hline
\end{tabular}

TABLE 2: Ocean heat content change $\left(\times 10^{24} \mathrm{~J}\right)$.

\begin{tabular}{lcccccrrr}
\hline & \multicolumn{3}{c}{ Whole water depth } & \multicolumn{3}{c}{$0-2000 \mathrm{~m}$} \\
& IPSL & MIROC & MPI & MRI & IPSL & MIROC & MPI & MRI \\
\hline Global & -7.39 & -9.96 & -10.70 & -11.25 & -5.43 & -6.08 & -5.78 \\
Atlantic & -1.88 & -1.88 & -1.86 & -2.23 & -1.31 & -1.32 & -0.94 & -1.27 \\
Arctic & -0.14 & -0.13 & -0.10 & -0.08 & -0.09 & -0.09 & -0.07 & -0.04 \\
Pacific & -2.78 & -4.08 & -4.41 & -4.59 & -2.04 & -2.46 & -2.30 & -2.33 \\
Indian & -1.08 & -1.18 & -1.45 & -1.58 & -0.82 & -0.72 & -0.82 & -0.96 \\
Southern & -1.31 & -2.72 & -2.69 & -2.60 & -0.98 & -1.47 & -1.46 & -1.56 \\
\hline
\end{tabular}

the surface cooling pattern. However, the South Atlantic demonstrates the strongest cooling in IPSL, MIROC, and MRI models. Strong cooling in the Indian and Southern Oceans is also presented in the MRI model.

The water body between 1000-2000 $\mathrm{m}$ experiences a moderate cooling of $-2^{\circ} \mathrm{C}$ (Figures $1(\mathrm{~d}), 1(\mathrm{e})$ and $1(\mathrm{f})$ ). All the four models have shown that north of the Gulf Stream region and South Atlantic experience more significant cooling than the rest of the regions. The Southern Ocean around $40^{\circ} \mathrm{S}$ has a larger amount of cooling as well. It is of note that the eastern boundary of the North Atlantic shows the slightest cooling and even warming in the MPI model.

The four models differ remarkably below $2000 \mathrm{~m}$ (Figures $1(\mathrm{f})$ and $1(\mathrm{~g}))$. The IPSL model only shows a cooling of about $-1.0^{\circ} \mathrm{C}$ in the large expanse with a maximum cooling of $-2.5^{\circ} \mathrm{C}$ south of the Greenland whilst the Southern Ocean shows merely slight cooling. But, the other three models of MIROC, MPI, and MRI show a much stronger cooling of greater than $-2^{\circ} \mathrm{C}$. The MIROC shows the strongest cooling in the Southern Ocean. But, MRI shows strong cooling in the Indian and Southern Oceans.

3.2. Latitudinal Cross Sections and Depth Variations. Figure 2 reveals that large cooling occurs in the upper $1000 \mathrm{~m}$. The temperate and tropical zones between $40^{\circ} \mathrm{S}-40^{\circ} \mathrm{N}$ are marked by subsurface cooling. The northern high latitude north of $40^{\circ} \mathrm{N}$ experiences maximum surface cooling. It is of note that the deep Arctic Ocean experiences the largest cooling in MIROC and MRI whereas IPSL and MPI only show merely a subsurface cooling.

Ocean basins act differently. The cooling in the Atlantic (Figure 2(b)) penetrates to $3000 \mathrm{~m}$ with a strikingly subsurface cooling center between $20^{\circ} \mathrm{S}$ and $20^{\circ} \mathrm{N} .40^{\circ} \mathrm{N}-70^{\circ} \mathrm{N}$ shows a surface cooling.
Compared to the Atlantic and Arctic, the Pacific, and Indian demonstrate a shallower cooling. All four models show a maximum cooling around $40^{\circ} \mathrm{N}$. However, the cooling only penetrates to $600 \mathrm{~m}$ in IPSL and MPI, but the other two models have a deeper penetration depth.

Profiles of temperature anomaly in different ocean basins indicate that the largest surface cooling occurs in the North Atlantic (Figure 3). IPSL and MRI show a global average cooling of $-2.5^{\circ} \mathrm{C}$ whilst MIROC and MPI have a cooling of $-2^{\circ} \mathrm{C}$. The North and South Atlantic in IPSL and MIROC show a similar pattern with a maximum of $-5^{\circ} \mathrm{C}$ at $400-500 \mathrm{~m}$. The Arctic cooling has a similar pattern in the four models where the coolest zone lies in the deep ocean. The other basins all exhibit a rapid subsurface cooling variation in the upper ocean.

3.3. Ocean Heat Content. Ocean heat content (OHC) change reveals the integrated cooling. Figure 4 reveals the $\mathrm{OHC}$ change of the four models. The IPSL model shows most cooling happens in the Atlantic, parts of the Pacific and Indian. But MIROC, MPI, and MRI models demonstrate a much more significant cooling in the Pacific and Indian. Figure 5 lists the average and total $\mathrm{OHC}$ change. The North Pacific and Southern Ocean have the strongest change of average $\mathrm{OHC}$.

More than half of OHC change occurs above $2000 \mathrm{~m}$. Like temperature change in oceans, $\mathrm{OHC}$ change also takes place mainly in the upper ocean to $2000 \mathrm{~m}$ (Table 2). On a global scale, the upper $2000 \mathrm{~m}$ accounts for 73\%, 61\%, 54\%, and $56 \%$ in IPSL, MIROC, MPI, and MRI, respectively.

$\mathrm{OHC}$ change has its individual feature in the five Ocean basins. The $\mathrm{OHC}$ change in Atlantic, Arctic, and Indian is almost the same for the four models but differs in the North Pacific and Southern Ocean, which also affect the total OHC 

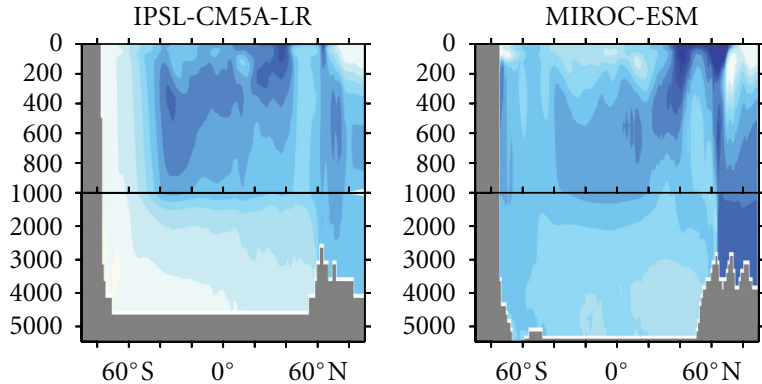
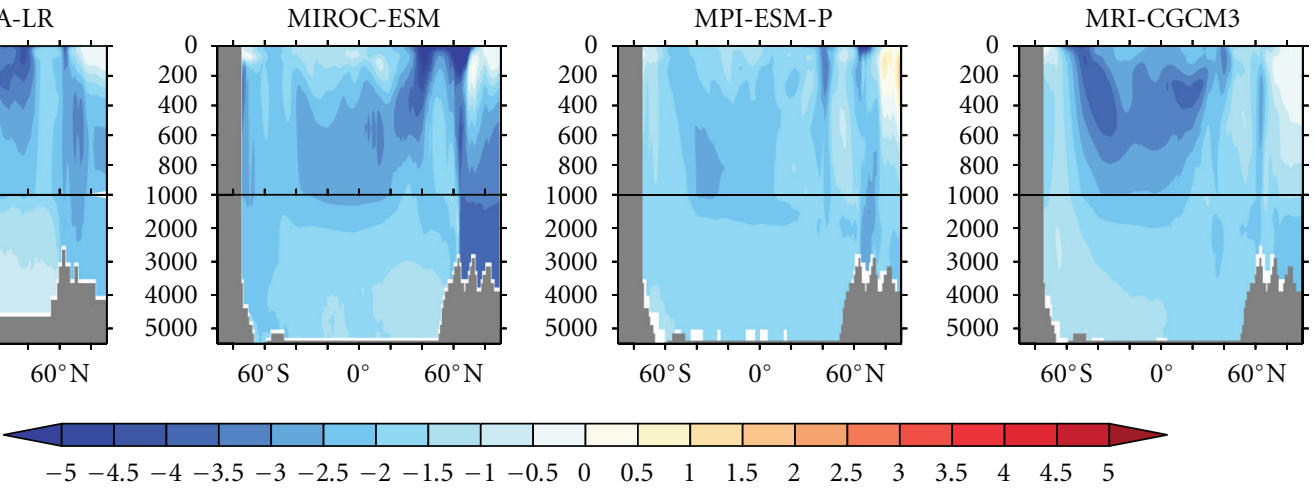

(a) Global
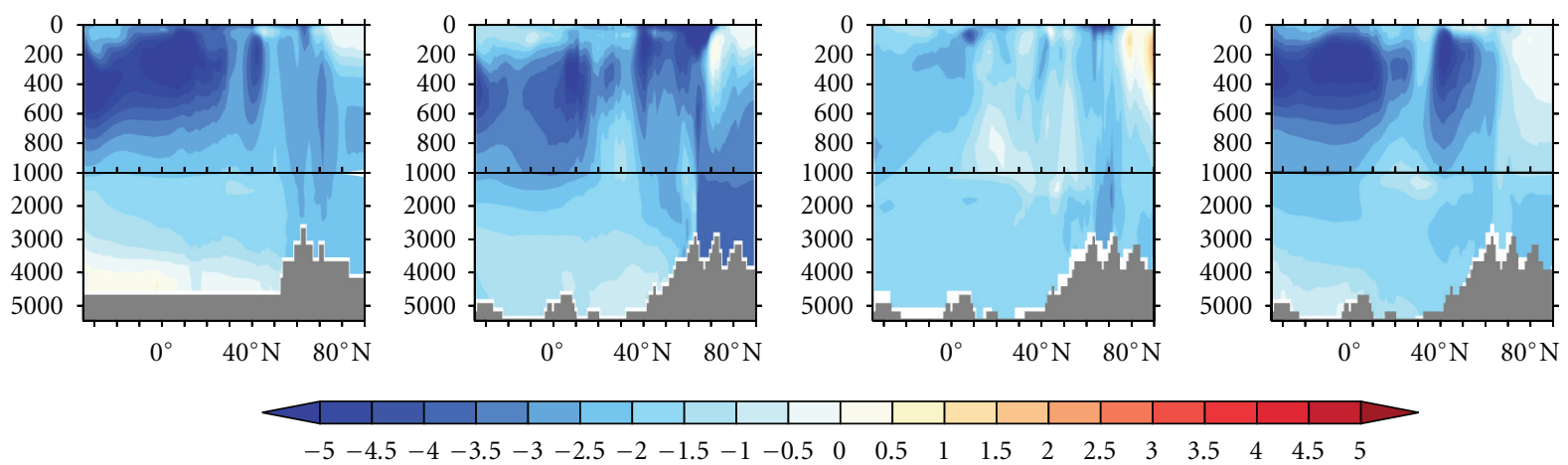

(b) Atlantic + Arctic
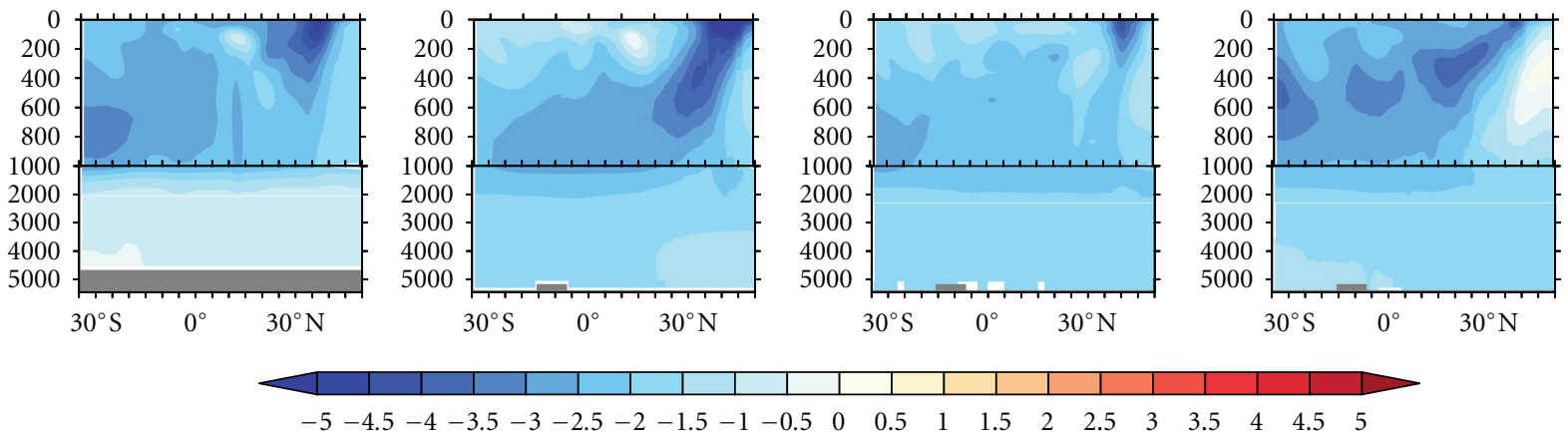

(c) Pacific + Indian

FIgURE 2: Latitudinal cross-sections of global mean (a) and ocean basins (b through c). The abscissa is latitude in degrees and the ordinate is water depth in meters. Notice that depth is unevenly distributed. The temperature anomaly is in ${ }^{\circ} \mathrm{C}$. Cooling occurs mostly in the upper ocean. Cooling in the Atlantic and Arctic Oceans is deeper than in the Pacific and Indian Oceans.

change (Figure 5(b)). It is of note that the $2000 \mathrm{~m} \mathrm{OHC}$ change is similar for all the four models and, therefore, the OHC change difference in the Pacific and Southern Ocean lies in the deep ocean.

\section{Discussions}

Unfortunately, not all PMIP3 models output ocean meridional overturning mass stream function. Among the four released model results, only MPI and MRI have meridional overturning variables. Meridional overturning circulation (MOC) changes are usually the responses to climate change. Here we explore the links between the MOC change and temperature anomaly on the global scale and regional scale at the Last Glacial Maximum.

Previous studies have revealed that cooling at the Last Glacial Maximum is closely related to meridional overturning circulation (MOC) [7-9]. They simulated a shallower and weaker North Atlantic Deep Water circulation and an enhanced intrusion of Antarctic Bottom Water (AABW) into 


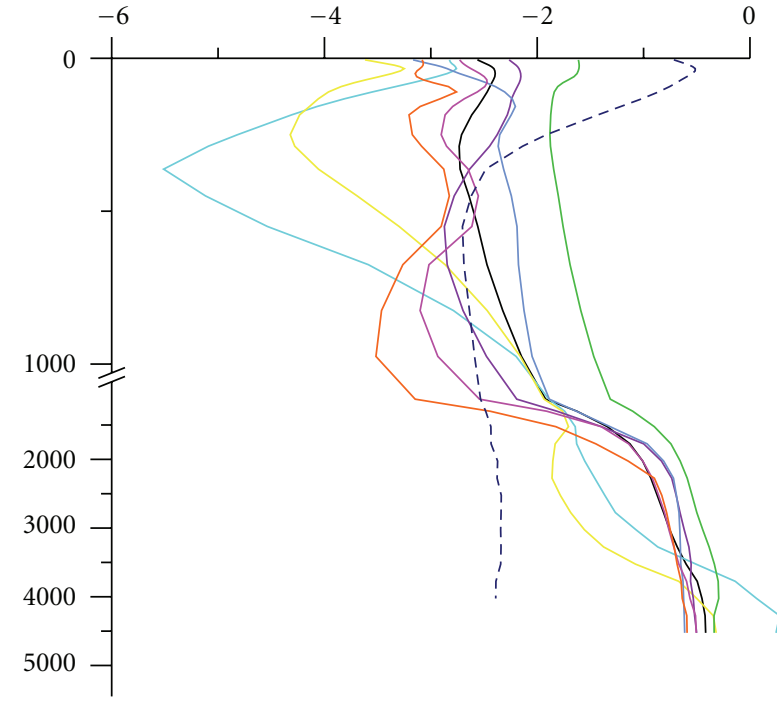

(a) IPSL-CM5A-LR

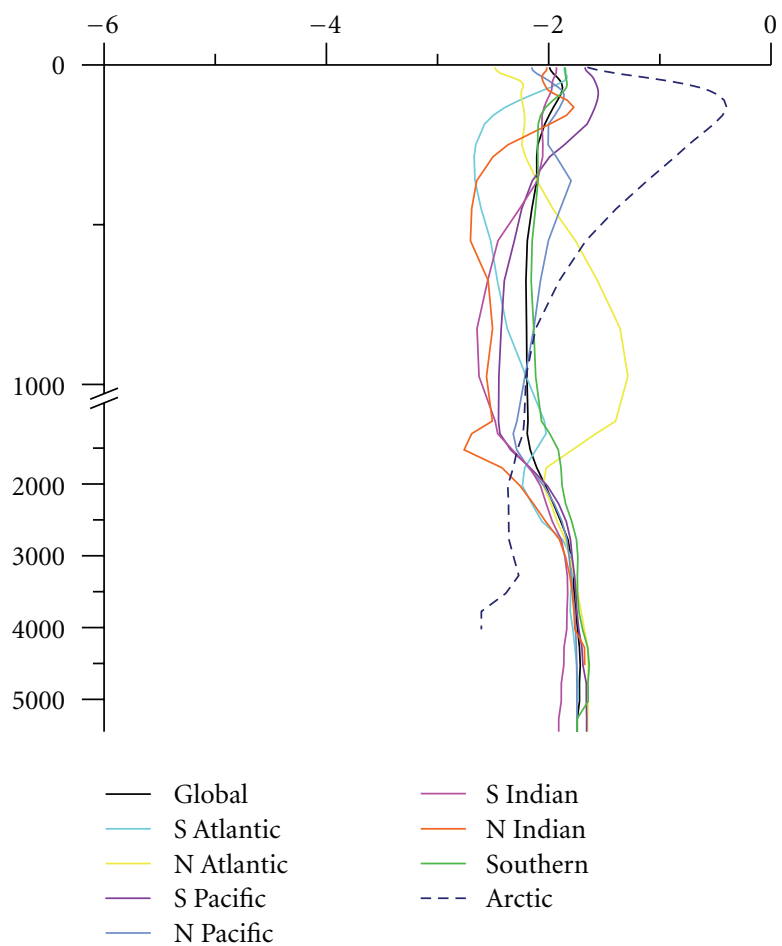

(c) MPI-ESM-P

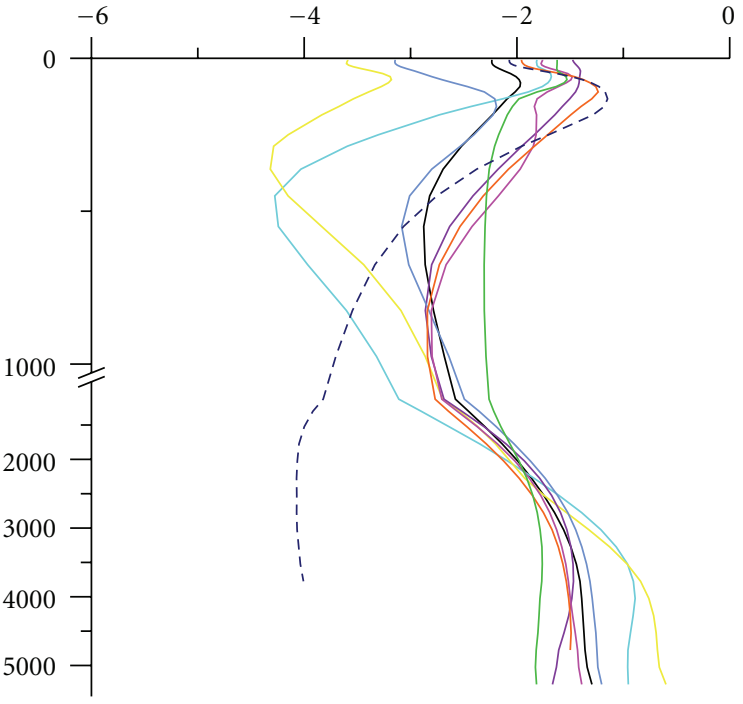

(b) MIROC-ESM
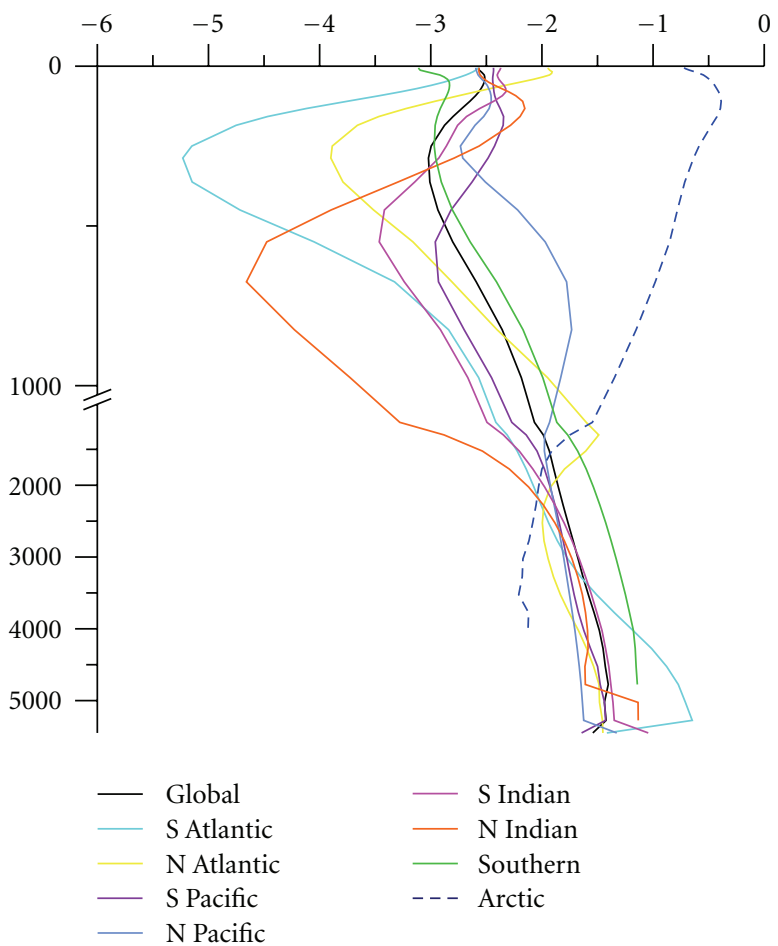

(d) MRI-CGCM3

Figure 3: Ocean cooling profiles of global mean and ocean basins. The abscissa is temperature anomaly in ${ }^{\circ} \mathrm{C}$ and the ordinate is water depth in $\mathrm{m}$. The maximum surface warming occurs in the North Atlantic. Ocean cooling mostly concentrates in the upper $1000 \mathrm{~m}$ with rapid variations in different basins.

the North Atlantic [10]. Ganopolski and Rahmstorf [8] proposed a cold mode MOC to explain the cooling mechanism at the Last Glacial Maximum.

On a global scale the upper $2000 \mathrm{~m}$ witnesses a weakening trend of the MOC although the magnitude varies in the two models (Figure 6(a)). MPI presents a negative MOC anomaly whilst MRI only shows a slight decrease of MOC compared to the preindustrial run. In the deep part we can observe the enhancement of AABM. Both models exhibit the weakening of the Atlantic meridional overturning circulation (Figure 6(b)). Figures 1 and 2 have different temperature distributions with regard to MPI and MRI. Cooling in the upper Pacific and Indian Oceans simulated by MPI is not as strong as cooling by MRI, which is closely related to the enhanced MOC change in MPI upper ocean while MRI upper part shows a weakening MOC change. 


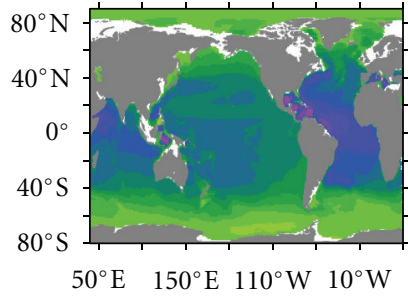

(a) IPSL-CM5A-LR

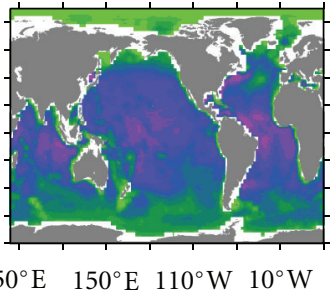

(b) MIROC-ESM

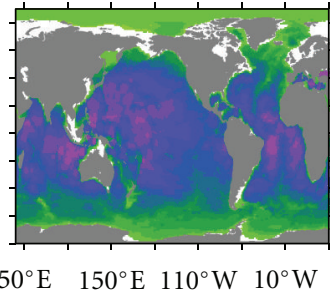

(c) MPI-ESM-P

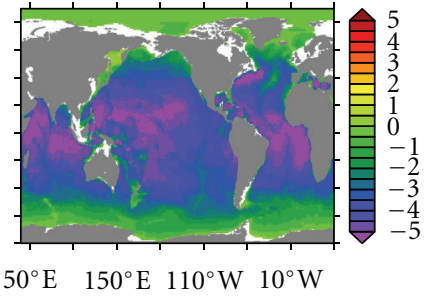

(d) MRI-CGCM3

FIGURE 4: Ocean heat content change $\left(\times 10^{10} \mathrm{Jm}^{-2}\right)$ at the Last Glacial Maximum. Most cooling occurs between $40^{\circ} \mathrm{S}$ and $40^{\circ} \mathrm{N}$. All the four models show cooling in the Atlantic. But, cooling in the Pacific and Indian Oceans varies.

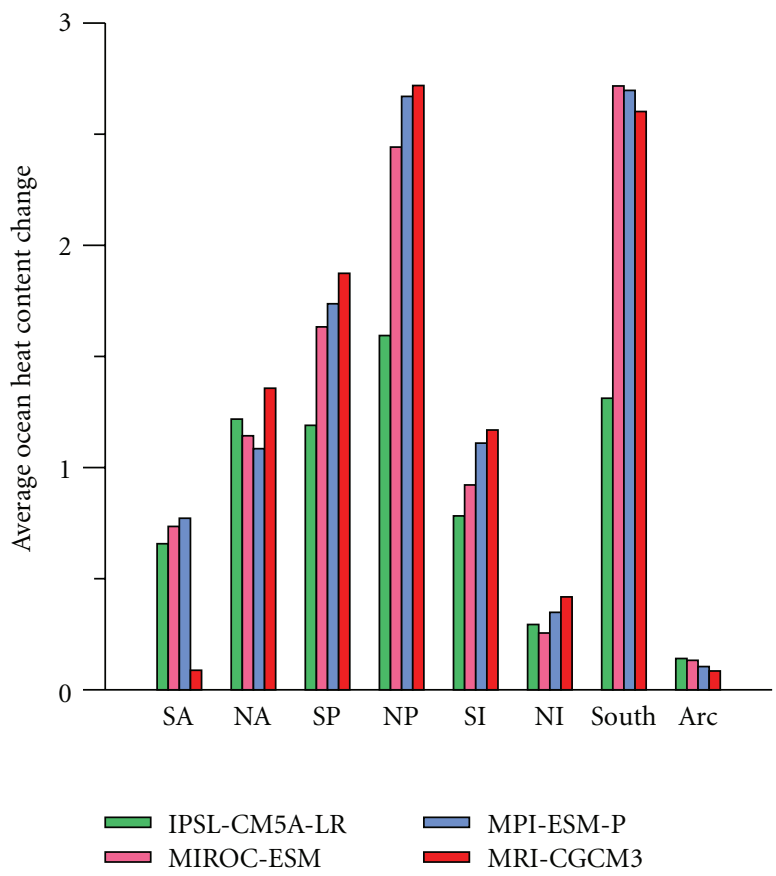

(a)

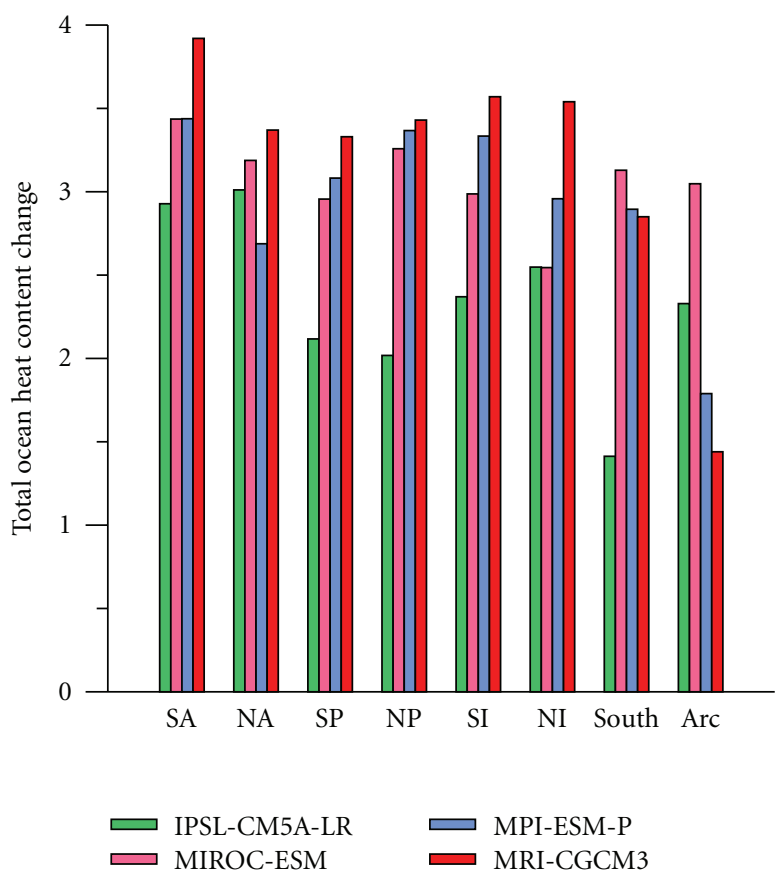

(b)

FIGURE 5: Ocean heat content change in ocean basins. (a) Average OHC change $\left(\times 10^{10} \mathrm{Jm}^{-2}\right)$ and (b) total OHC change $\left(\times 10^{24} \mathrm{~J}\right)$. Cooling in the North Pacific and Southern Ocean differs in magnitude among the four models. SA—South Atlantic, NA—North Atlantic, SP-South Pacific, NP—North Pacific, SI—South Indian, NI—North Indian, South—Southern Ocean, Arc—Arctic.

Based on the MOC change and temperature anomaly in these two models, we can see that weakening of MOC in the upper ocean is closely related to upper cooling and enhancement of AABW in the deep part is associated with cooling in the deep ocean.

\section{Summaries}

Although the four models differ in cooling magnitude, we see that cooling at the Last Glacial Maximum varies both horizontally and vertically. Cooling mostly occurs between $40^{\circ} \mathrm{S}$ and $40^{\circ} \mathrm{N}$ in the upper $1000 \mathrm{~m}$. More than half of $\mathrm{OHC}$ change happens in the upper $2000 \mathrm{~m}$.
All the four models are in agreement that ocean basins, except the Arctic, are featured by surface to subsurface cooling. Cooling in the Atlantic and Arctic is much deeper than the Pacific and Indian. The Atlantic experiences the greatest cooling at the Last Glacial Maximum. Ocean cooling at the Last Glacial Maximum is closely related to the MOC change.

\section{Acknowledgments}

We acknowledge the modeling groups, the Program for Climate Model Diagnosis and Intercomparison (PCMDI) and the WCRP's Working Group on Coupled Modeling 


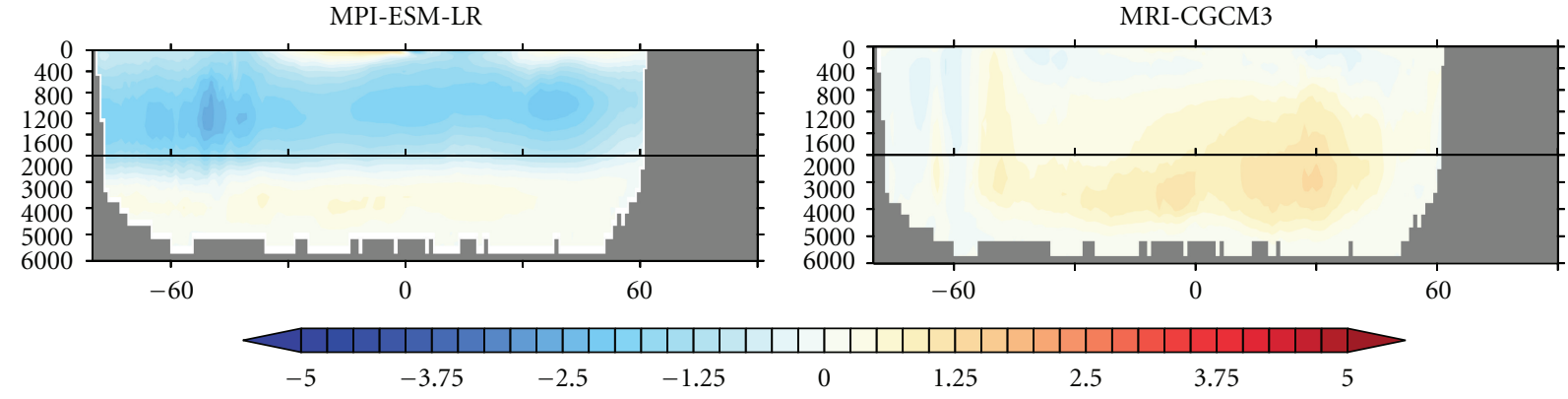

(a) Global

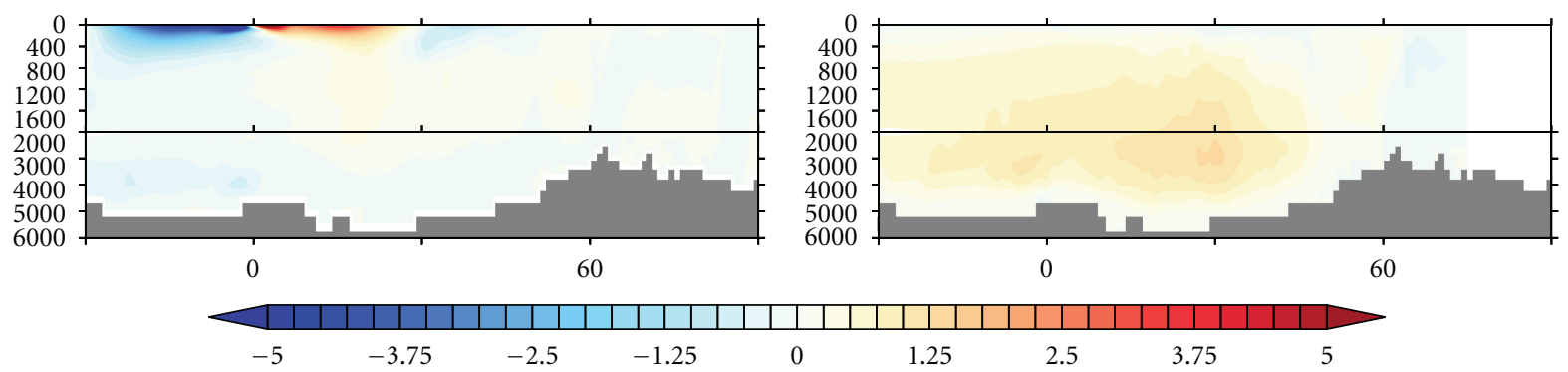

(b) Atlantic + Arctic

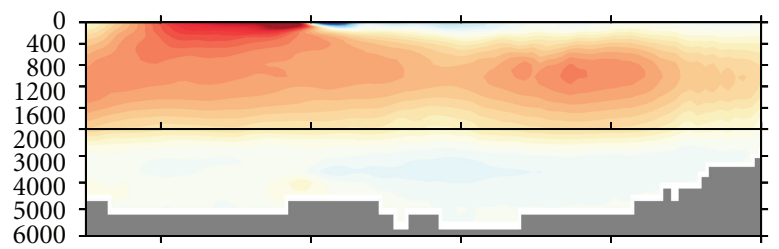

0

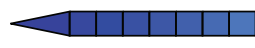

$-3.75$

40

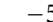

$-2.5$

$-1.25$

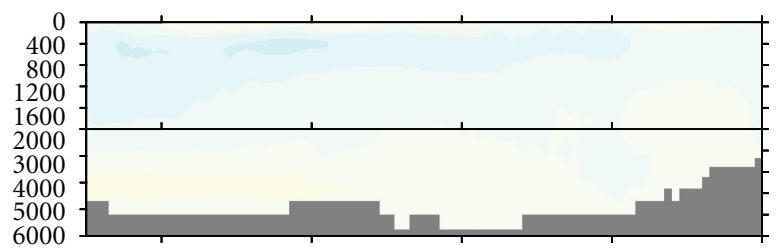

$6000+$

40

0

(c) Pacific + Indian

Figure 6: Ocean meridional overturning mass-stream function anomaly of global mean (a) and ocean basins (b through c). The abscissa is latitude in degrees and the ordinate is water depth in meters. Notice that depth is unevenly distributed. The overturning mass-stream function anomaly is in $\times 10^{10} \mathrm{kgs}^{-1}$. MOC weakens in the upper ocean whereas the AABW is enhanced. It is of note that MOC change in the Pacific and Indian Oceans are different in MPI and MRI.

(WGCM) for their roles in making available the WCRP CMIP5 multimodel dataset. Support of this dataset is provided by the Office of Science, US Department of Energy.

\section{References}

[1] A. Schmittner, N. M. Urban, J. D. Shakun et al., "Climate sensitivity estimated from temperature reconstructions of the Last Glacial Maximum," Science, vol. 334, pp. 1385-1388, 2011.

[2] Y. Okazaki, A. Timmermann, L. Menviel et al., "Deepwater formation in the North Pacific during the last glacial termination," Science, vol. 329, no. 5988, pp. 200-204, 2010.

[3] MARGO Project Members, "Constraints on the magnitude and patterns of ocean cooling at the Last Glacial Maximum," Nature Geoscience, vol. 2, pp. 127-132, 2009.

[4] M. Kageyama, A. Laîné, A. Abe-Ouchi et al., "Last Glacial Maximum temperatures over the North Atlantic, Europe and western Siberia: a comparison between PMIP models,
MARGO sea-surface temperatures and pollen-based reconstructions," Quaternary Science Reviews, vol. 25, no. 17-18, pp. 2082-2102, 2006.

[5] A. J. Weaver, M. Eby, A. F. Fanning, and E. C. Wiebe, "Simulated influence of carbon dioxide, orbital forcing and ice sheets on the climate of the Last Glacial Maximum," Nature, vol. 394, no. 6696, pp. 847-853, 1998.

[6] P. Braconnot, B. Otto-Bliesner, S. Harrison et al., "Results of PMIP2 coupled simulations of the Mid-Holocene and last glacial maximum-part 1: experiments and large-scale features," Climate of the Past, vol. 3, no. 2, pp. 261-277, 2007.

[7] A. Ganopolski, S. Rahmstorf, V. Petoukhov, and M. Claussen, "Simulation of modern and glacial climates with a coupled global model of intermediate complexity," Nature, vol. 391, no. 6665, pp. 351-356, 1998.

[8] A. Ganopolski and S. Rahmstorf, "Rapid changes of glacial climate simulated in a coupled climate model," Nature, vol. 409, no. 6817, pp. 153-158, 2001. 
[9] A. F. Thompson and S. Rahmstorf, "Ocean circulation," in Surface Ocean-Lower Atmosphere Processes, C. L. Quere and E. S. Saltzman, Eds., Geographical Monograph 187, pp. 99118, American Geophysical Union, 2009.

[10] S. I. Shin, Z. Liu, B. L. Otto-Bliesner, J. E. Kutzbach, and S. J. Vavrus, "Southern Ocean sea-ice control of the glacial North Atlantic thermohaline circulation," Geophysical Research Letters, vol. 30, no. 2, pp. 68-1, 2003. 

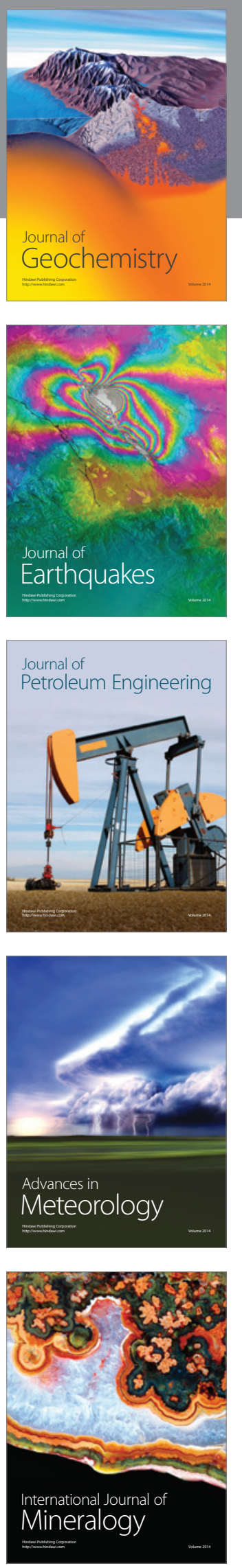
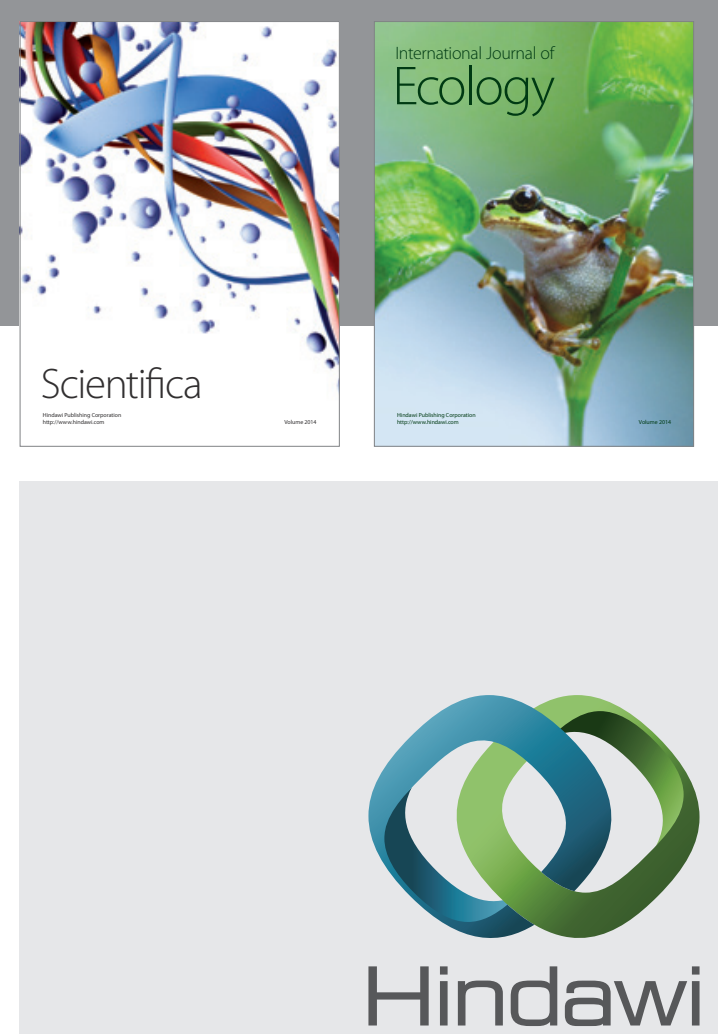

Submit your manuscripts at http://www.hindawi.com
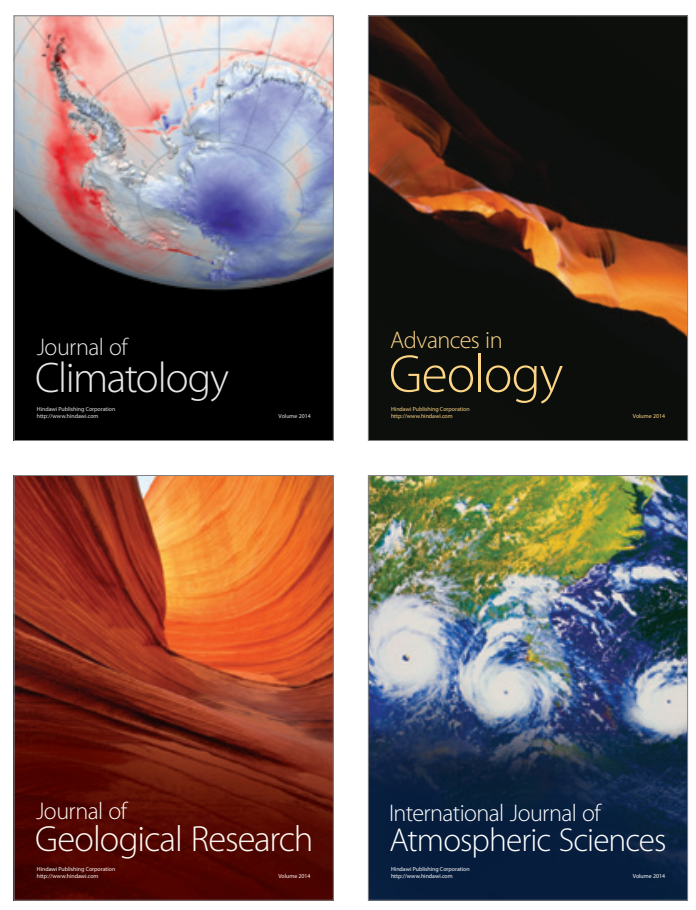
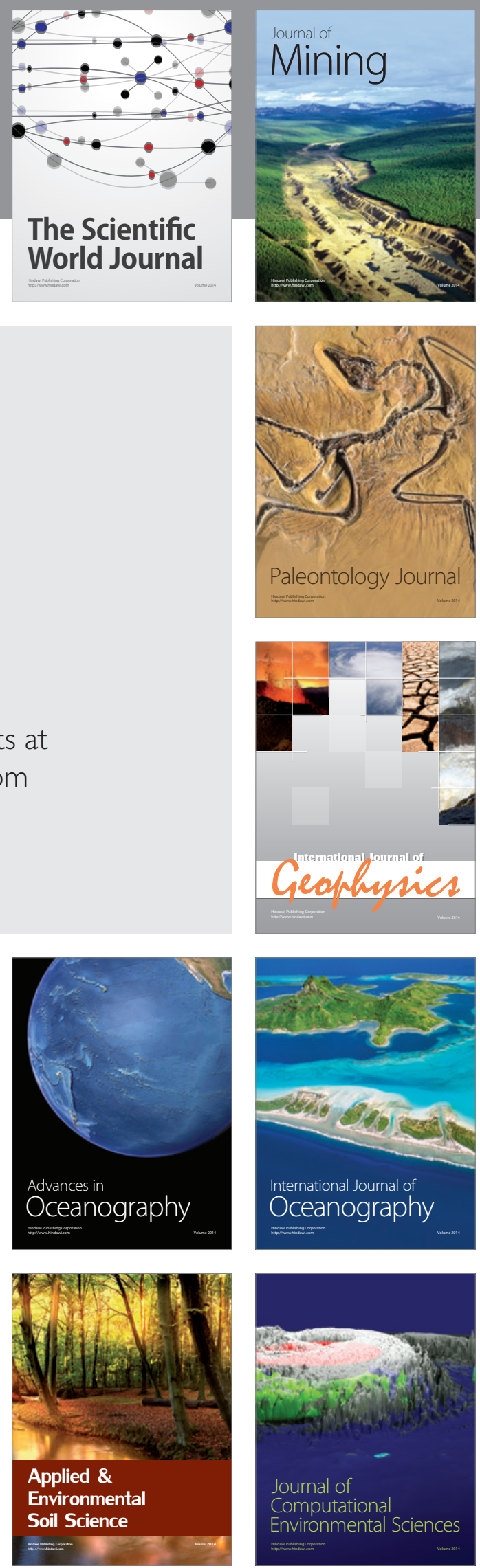